\title{
Resveratrol and Alzheimer's disease: message in a bottle on red wine and cognition
}

\author{
Alberto Granzotto ${ }^{1}$ and Paolo Zatta ${ }^{2}$ \\ ${ }^{1}$ Molecular Neurology Unit, Center of Excellence on Aging (Ce.S.I.), Chieti, Italy \\ ${ }^{2}$ CNR-Institute for Biomedical Technologies, Padua "Metalloproteins" Unit, Department of Biology, University of Padua, Padua, Italy
}

\author{
Edited by: \\ Paul Adlard, The Mental Health \\ Research Institute, Australia \\ Reviewed by: \\ Ana I. Duarte, University of \\ Coimbra, Portugal \\ Ashok K. Shetty, Institute for \\ Regenerative Medicine, Texas A \\ and $M$ Health Science Center \\ College of Medicine at Scott and \\ White, USA

\section{*Correspondence:} \\ Paolo Zatta, CNR-Institute for \\ Biomedical Technologies, Padua \\ "Metalloproteins" Unit, \\ Department of Biology, University \\ of Padua, Viale G. Colombo, 35121 \\ Padua, Italy \\ e-mail: zatta@bio.unipd.it
}

\begin{abstract}
Cognitive impairment is the final outcome of a complex network of molecular mechanisms ultimately leading to dementia. Despite major efforts aimed at unraveling the molecular determinants of dementia of Alzheimer type (DAT), effective disease-modifying approaches are still missing. An interesting and still largely unexplored avenue is offered by nutraceutical intervention. For instance, robust epidemiological data have suggested that moderate intake of red wine may protect against several age-related pathological conditions (i.e., cardiovascular diseases, diabetes, and cancer) as well as DAT-related cognitive decline. Wine is highly enriched in many polyphenols, including resveratrol. Resveratrol is a well recognized antioxidant which may modulate metal ion deregulation outcomes as well as main features of the Alzheimer's disease (AD) brain. The review will discuss the potentiality of resveratrol as a neuroprotectant in dementia in relation to the oxidative stress produced by amyloid and metal dysmetabolism.
\end{abstract}

Keywords: resveratrol, Alzheimer's disease, aging, metal ions, aluminum, copper, iron, zinc

\section{INTRODUCTION}

The so-called French paradox arises from the epidemiological fact that French people, despite their indulgence to a high fat diet, show a relative low incidence of cardiovascular diseases (Renaud and De Lorgeril, 1992). Several epidemiological studies have shown that moderate wine consumption can be effective in slowing down age-related cognitive decline (Wang et al., 2006; Panza et al., 2012; Corona et al., 2013). A possible explanation of this phenomenon has been linked to the national high consumption of wine (20-30 g/day) (Renaud and De Lorgeril, 1992). Albeit moderate ethanol intake is, generally speaking, "beneficial", some more specific effects appear to be related to red wine. Red wine consumption seems in fact to promote far more protective effects than consumption of other ethanol containing beverages (Baur and Sinclair, 2006). Resveratrol, a natural polyphenol, is mainly present in red wine and has been suspected to be the major driving force behind the French paradox (Siemann and Creasy, 1992).

$\mathrm{AD}$ is one of the most common forms of dementia in the elderly. To date, no disease-modifying therapies are still available for $\mathrm{AD}$.

The main four pathological features of the disease are: (1) extracellular deposition of misfolded $\beta$-amyloid $(A \beta)$ in senile plaques (SPs); (2) intracellular accumulation of hyperphosphorylated tau in neurofibrillary tangles (NFTs); (3) severe brain atrophy; and (4) the presence of areas of chronic inflammation (Querfurth and Laferla, 2010; Medeiros et al., 2013).

In the last 20 years, deregulation of $A \beta$ metabolism (amyloid oligomerization, aggregation, and plaques formation) has been considered the main trigger for AD-related synaptic dysfunction. Amyloid has been therefore the major target for therapeutic intervention (Hardy and Higgins, 1992; Mucke and Selkoe, 2012). Unfortunately, most of these attempts have dramatically failed or have produced only marginal effects (Reitz, 2012; Krstic and Knuesel, 2013; Doody et al., 2014).

Better therapeutic strategies are thus needed along with new acknowledgment that $\mathrm{AD}$ is a complex multifactorial syndrome.

Aging is the required paramount condition (Herrup, 2010) on which, in addition to $A \beta$ together with tau deregulation, genes, chronic inflammation, mitochondrial, metabolic dysfunctions, impaired insulin signaling, oxidative stress, aberrant cell cycle reentry, cholesterol dysmetabolism as well as metal ion dyshomeostasis must synergistically work to promote AD pathological manifestation (Herrup, 2010; Querfurth and Laferla, 2010; Roberts et al., 2012). While a single-target therapeutic strategy seems to produce only suboptimal results a broader neuroprotective approach, at least theoretically, appears more appealing (Mudher and Lovestone, 2002).

In this review, we are providing some evidence for resveratrol as a broad-spectrum neuroprotective agent in aging and hopefully in AD.

\section{RESVERATROL}

Resveratrol has beneficial cardiovascular effects (Siemann and Creasy, 1992) throughout a great variety of molecular mechanisms (Howitz et al., 2003; Baur and Sinclair, 2006; Lagouge et al., 2006; Park et al., 2012). 
A recent review on aging determinants has proposed nine hallmarks for the process (López-Otín et al., 2013). Not surprisingly, almost all of them are also involved in $\mathrm{AD}$ development and progression (Figure 1; Herrup, 2010; Querfurth and Laferla, 2010) and, notably, at least five, are well recognized target for resveratrol modulation.

In the following sections we have outlined potential effects of resveratrol on these aging and/or $\mathrm{AD}$ molecular targets.

\section{$\beta$-AMYLOID AND HYPERPHOSPHORYLATED TAU MISFOLDING}

Blockade of $A \beta$ deposition into SPs and inhibition of hyperphosphorylation of tau into NFTs has been considered mandatory to prevent or, at least, delay $\mathrm{AD}$-related cognitive decline.

Resveratrol has been shown to inhibit $A \beta$ fibrils formation (Porat et al., 2006; Rivière et al., 2007). Moreover, in vitro and in vivo studies have also indicated that resveratrol reduces amyloid toxicity by decreasing $A \beta$ production through sirtuindependent activation of a disintegrin and metalloproteinase domain-containing protein 10 (Donmez et al., 2010). The compound also increases clearance and metabolism via an AMPactivated protein kinase-pathway and can induce autophagic and lysosomal A $\beta$ degradation (Marambaud et al., 2005; Vingtdeux et al., 2010). Resveratrol can effectively interject in the amyloid cascade through its antioxidant and anti-inflammatory activity, thereby reducing $A \beta$-driven production of reactive oxygen species (ROS) as well as neuroinflammation (Liu and Bitan, 2012).

Effects on tau phosphorylation and deposition have been less investigated. However, resveratrol-mediated activation of sirtuin-1 (SIRT1) can lead to direct deacetylation of acetylated tau, thereby promoting its proteasomal degradation (Min et al., 2010). In addition, the compound can reduce phospho-tau toxicity (induced by cyclin-dependent kinase 5-p25 dependent tau phosphorylation) by favoring the deacetylation of peroxisome proliferator-activated receptor gamma, coactivator 1 alpha (PGC$1 \alpha)$ and p53 (Kim et al., 2007).

\section{CELLULAR METABOLISM}

Caloric restriction has been proposed to be effective in increasing lifespan in several animal models. Fasting has been observed to promote beneficial effects on preclinical models of AD and aging not only by extending lifespan but also by ameliorating cognitive performances (Halagappa et al., 2007). Caloric restriction can in fact promote release of brain-derived neurotrophic factor (BDNF), a neurotrophin critically involved in counteracting cognitive decline (Weinstein et al., 2014).

In this context, resveratrol efficiently mimics caloric restriction by inducing expression of SIRT1 (a nicotinamide adenine dinucleotide $\left(\mathrm{NAD}^{+}\right)$dependent deacetylase) which in turn sets in motion a cascade of PGC- $1 \alpha$-dependent events that ultimately lead to improved mitochondrial functioning and biogenesis and boost cellular ROS scavenging (Gomes et al., 2013; López-Otín et al., 2013).

\section{INFLAMMATION}

Areas of localized inflammation and active microglia contribute to neurodegeneration and cognitive decline in $\mathrm{AD}$ brains

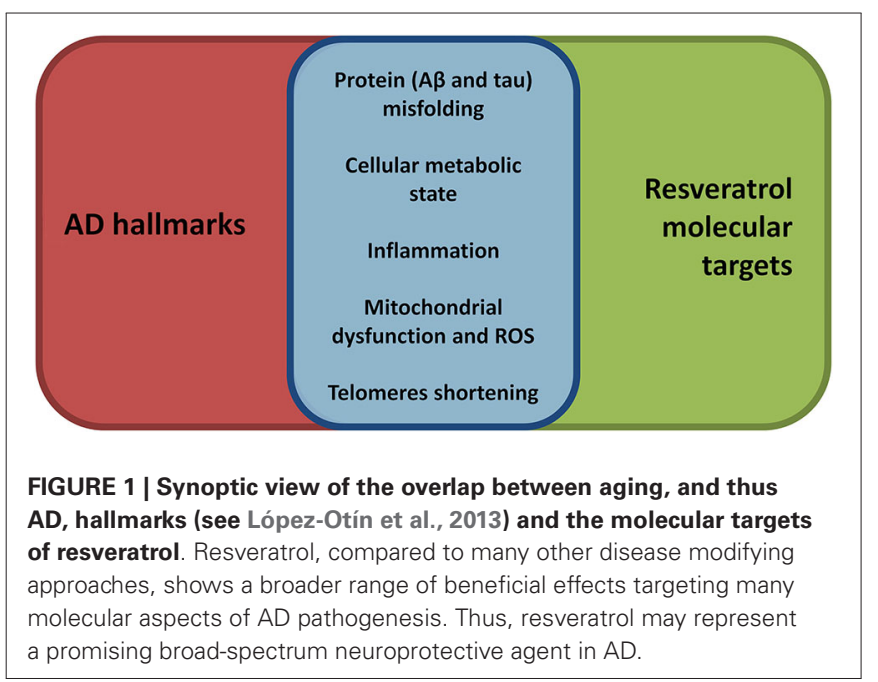

(McGeer and McGeer, 2013). Pharmacological and genetic manipulations aimed at reducing brain inflammation appear to be effective in slowing/modifying the disease progression in $\mathrm{AD}$ animal models (Heneka et al., 2013; Giuliani et al., 2014).

Resveratrol is effective in reducing the inflammatory status (Rahman et al., 2006; Chen et al., 2013) in in vitro and in vivo settings of neuroinflammation (Capiralla et al., 2012; Frozza et al., 2013).

Mechanisms by which resveratrol attenuate neuroinflammation are still not completely clear. A major pathway seems to involve sirtuin-dependent arrest of nuclear factor kappa-lightchain-enhancer of activated B cells signaling cascades, a step that results in downstream blockade of microglia activation (Capiralla et al., 2012; Donmez, 2012; Ye et al., 2013).

\section{MITOCHONDRIAL DYSFUNCTION AND ROS}

Mitochondria play an essential role in the cell wellbeing. The organelles critically control cellular energy and metabolism as well as intracellular signaling (Rizzuto et al., 2012). On the dark side, mitochondria are also key players in modulating cellular death through release of apoptotic factors, blockade of energy supply and generation and release of ROS. Alterations of mitochondrial functioning are known in aging and early stages of $\mathrm{AD}$ (Wang et al., 2013).

Mitochondrial electron leakage, followed by ROS production occurs in neurodegenerative conditions paving the way to lipid peroxidation, nucleic acid damage, protein oxidation, and, eventually, neuronal death (Wang et al., 2013).

Resveratrol counteracts the production of mitochondrial ROS through two major mechanisms: (1) by efficiently scavenging hydroxyl, superoxide, and metal-induced radicals (Leonard et al., 2003); and (2) by increasing mitochondrial functioning and biogenesis through activation of the SIRT1-PGC-1 $\alpha$ pathway, thereby boosting mitochondrial bioenergetic efficiency (Khan et al., 2012; Choi et al., 2013; Desquiret-Dumas et al., 2013).

\section{TELOMERES SHORTENING}

Telomeres shortening plays a key role in cellular aging and AD (Cai et al., 2013; Mathur et al., 2014). Short telomeres increase 
DNA vulnerability to stressful insults (i.e., UV irradiation, ROS production) ultimately leading to aberrant cell functioning and cell death. Polyphenols has a positive impact upon maintenance of telomeres length (Jayasena et al., 2013). In that respect, resveratrol promotes the expression of Werner syndrome ATP-dependent helicase, a telomere maintenance factor (Uchiumi et al., 2011), increases the activity of telomerase via a SIRT1-dependent pathway (Palacios et al., 2010), and spares telomeres and DNA from ROS dependent damages thanks to its intrinsic scavenging properties (Jayasena et al., 2013).

\section{METAL IMBALANCE IN THE AD BRAIN: A POTENT TRIGGER OF OXIDATIVE STRESS}

In the brain, metal ions are involved in many essential processes such as intracellular signaling, modulation of cellular redox and metabolic states, enzymatic activities and channels functioning (Billard, 2006; Sensi et al., 2009; Rizzuto et al., 2012; Sekler and Silverman, 2012; Gaier et al., 2013). Metal homeostasis is strictly controlled by the interplay of transporters, channels, chaperones and metalloregulatory sensors (Finney and O'halloran, 2003). In neurodegenerative conditions and/or aging, this tightly controlled system is lost, thereby leading to disease-promoting metal imbalance (Bolognin et al., 2009; Breydo and Uversky, 2011; Jellinger, 2013).

Metal ion dyshomeostasis is in fact involved in several neurological disorders like Parkinson's disease (PD), Amyotrophic Lateral Sclerosis (ALS), Prion Protein disease, Huntington's disease (HD), and AD. All these neurodegenerative conditions share common pathological features that include deposition of misfolded proteins, metal ion deregulation and exposure to oxidative stress (Boillee et al., 2006; Duce and Bush, 2010; Roberts et al., 2012; Gonzalez-Dominguez et al., 2014).

In $\mathrm{AD}$, metal ion dyshomeostasis represents a key, though too often overlooked, pathological step. A metal hypothesis for $\mathrm{AD}$ has been proposed by many authors (Bush, 2008). In that respect, copper, iron, zinc and aluminum are the metals found deregulated in $\mathrm{AD}$. All of them are able to alter $\mathrm{A} \beta$ metabolism and deposition (Bolognin et al., 2011). SPs but also NFTs are highly enriched of these metals. Moreover, all these ions can promote ROS generation (Sayre et al., 2000; Granzotto and Zatta, 2011; Pithadia and Lim, 2012; Ayton et al., 2013).

Recent findings have shown that low levels of copper are sufficient to dramatically affect $A \beta$ homeostasis by increasing $A \beta$ accumulation and neuroinflammation related to $A \beta$-deposition (Singh et al., 2013). Compared to nondemented elderly controls, brains of AD patients show an increased presence of labile copper pools, which correlate with oxidative damage in these tissues (James et al., 2012). Resveratrol is a well known copper chelator (Tamboli et al., 2011) and, in theory, of some use in AD (Faux et al., 2010). Unfortunately, the copper-resveratrol complex seems to be more harmful than beneficial in the context of AD. Resveratrol promotes the reduction of copper (II) to copper (I) (de la Lastra and Villegas, 2007) and several studies have indicated a pro-oxidant activity of the compound when bound to copper (Zheng et al., 2006; de la Lastra and Villegas, 2007; Muqbil et al., 2012). Thus, resveratrol activity on copper homeostasis appears more harmful than neuroprotective if used as standalone therapeutic approach. A feasible and, in our opinion, clinically relevant approach might be represented by the administration of resveratrol in association with a higher affinity copper chelator. This would lead, at least in theory, to a dual beneficial effect: reduction of copper dyshomeostasis coupled with decreased ROS production.

Iron deregulation has been linked to $\mathrm{AD}$ (Weinreb et al., 2013; Crespo et al., 2014; Gonzalez-Dominguez et al., 2014). Role of iron in $\mathrm{AD}$ pathogenesis is substantiated by the effectiveness of metal homeostatic therapies aiming at reducing iron deregulation (Crouch et al., 2007), which results in (1) decreased free iron accumulation and ferroptosis (Dixon et al., 2012); (2) decreased iron-dependent ROS production; and (3) blockade of neurotoxic $A \beta$-iron conjugates formation (Liu et al., 2012). To date, in vivo evidence for iron chelation by resveratrol is missing, however the compound prevents iron-driven mitochondrial dysfunction by inhibiting glycogen synthase kinase-3 beta activity (a mechanism useful also to prevent tau hyperphosphorylation) (Shin et al., 2009), and by reducing peroxidation of lipoproteins and lipids through its activity as scavenger (Belguendouz et al., 1997; Tadolini et al., 2000).

Zinc dyshomeostasis has been proposed as a risk factor for AD. Accumulation of excessive zinc, or its deficiency, are both involved in the neuronal loss which leads to $\mathrm{AD}$ and aging related cognitive decline (Brewer, 2012). While zinc deficiency increases neuroinflammation and also affects BDNF maturation and ultimately cognition, aberrant intracellular zinc mobilization or accumulation leads to mitochondrial failure and ROS production. Extracellular zinc overload within SPs also inhibits the iron-export ferroxidase activity further increasing ROS production and ultimately neuronal death (Duce et al., 2010). Resveratrol does not directly affect zinc levels however it can be useful in preventing the full development of zincdependent injurious mechanisms. Actually, resveratrol inability to sequester zinc does not represent a limitation, as the compound can exert antioxidant activities without producing zinc deficiency.

Aluminum lacks modulatory functions in biological processes; however, its accumulation in the brain has been demonstrated to be linked to several neuropathological conditions (Zatta et al., 2003; Walton, 2013). To date three are the main mechanisms through which aluminum exerts its neurotoxic effects: (1) production of ROS; (2) induction of neuroinflammation; and (3) formation of toxic aggregates of misfolded proteins (Perl, 2006; Kumar et al., 2009; Wu et al., 2012; Bolognin et al., 2013). In AD, aluminum seems to act as an effective cross-linker between tau phospho-sites, to "freeze" $\mathrm{A} \beta$ in its toxic oligomeric state, and to induce exposure of $\mathrm{A} \beta$ hydrophobic clusters aggregates, thereby boosting toxic properties of these misfolded proteins (Zatta et al., 2009; Bolognin et al., 2011; Chen et al., 2011; Granzotto et al., 2011). Aluminum-related oxidative damage occurs through lipid peroxidation, alteration of the activity of antioxidant enzymes, alterations of mitochondrial functioning and biogenesis and promotion of DNA injury (Zatta et al., 2002; Sharma et al., 2013). Resveratrol shows a negligible ability to bind aluminum in vitro 


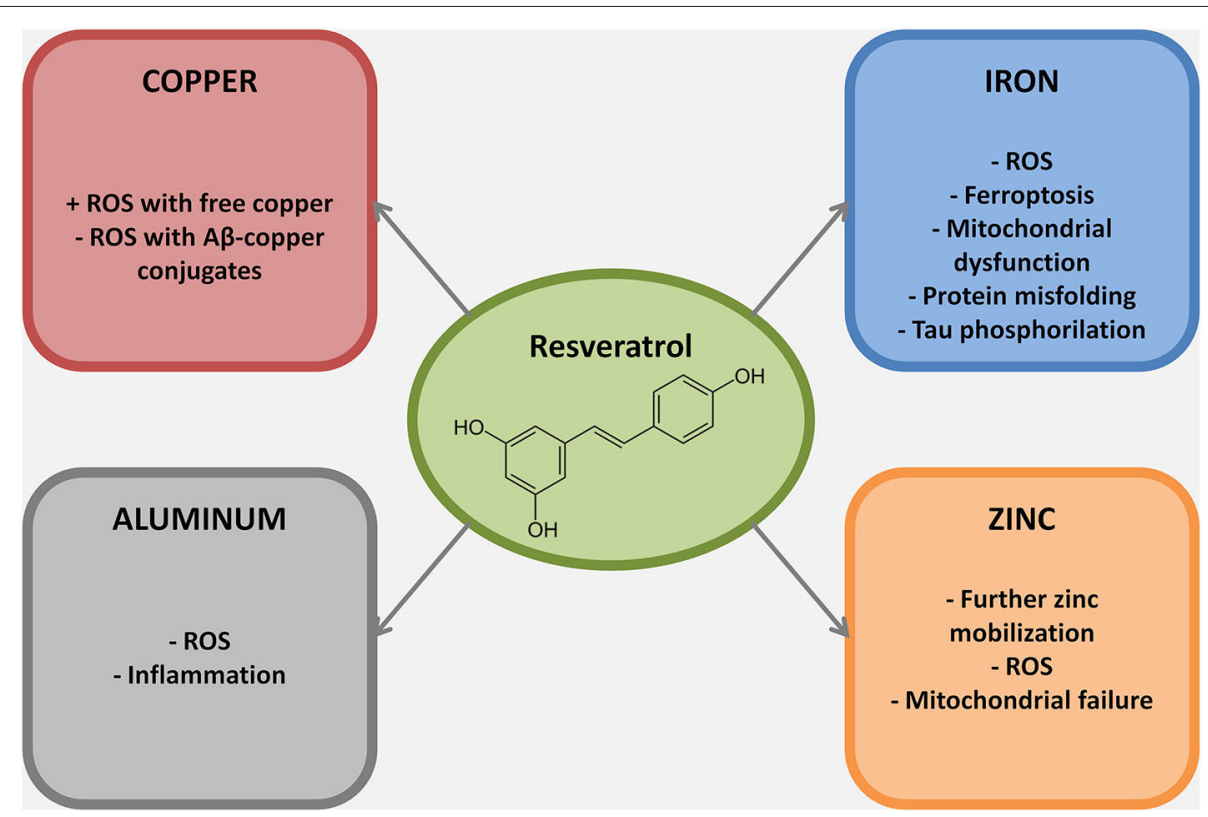

FIGURE 2 | Metal ions dyshomeostasis is closely related to different hallmarks of AD pathogenesis, mainly protein misfolding, ROS production, mitochondrial failure and inflammation. In this figure the mechanisms through which resveratrol exert its neuroprotective role against selected metal ions are reported. Of note, most of the resveratrol beneficial effects against metal ion dyshomeostasis belong to its scavenging properties.
(Granzotto and Zatta, 2011), nevertheless, it seems effective in reducing in vivo the downstream events of aluminum overload, namely the aluminum-related ROS production and neuroinflammatory response activation (Zaky et al., 2013).

\section{CONCLUSIONS}

Resveratrol is a multi target compound and may represent an effective therapeutic tool in aging-related neurodegenerative processes. Consistently, several clinical trials are ongoing to test its effectiveness as dietary supplement to slow dementia progression (ClinicalTrials.gov, 2014).

In summary, major effects are associated with its scavenging activity as well as in the activation of SIRT1 (see Bordone and Guarente, 2005; Herskovits and Guarente, 2014 for extensive reviews on the topic). The presence of non-SIRT1 neuronal targets of resveratrol is debated, suggesting that resveratrol in vivo may act on other uninvestigated biological targets (Herskovits and Guarente, 2014). The complementary role of modulator of metal dependent oxidative injury (Figure 2) represents a still largely unexplored field in resveratrol biochemistry.

Resveratrol is a multi-target, simple, safe, and cost-effective dietary supplement. Nevertheless, it should be reminded that its role as therapeutic agent is not devoid of potential problems. The pro-oxidant activity in presence of labile copper, the poor bioavailability and ease degradation all represent major issue that require new sophisticated efforts (Goldberg et al., 2003). Synthesis of novel resveratrol analogs is ongoing and improvement of drug delivery might represent in that regard the major targets to be considered in order to overcome current resveratrol limitations. In agreement, pterostilbene, a resveratrol derivative, has shown promise in preclinical models of neurodegeneration, resulting more efficient than resveratrol itself in modifying $\mathrm{AD}$ - and aging-related cognitive decline (Joseph et al., 2008; Chang et al., 2012). These results leave the door open for the use of newly synthesized resveratrol analogs in aging-related disorders (Bourzac, 2012; Ogas et al., 2013; Pezzuto et al., 2013).

\section{ACKNOWLEDGMENTS}

Authors are grateful to Prof. Stefano L. Sensi for fruitful discussions during manuscript preparation. Alberto Granzotto is supported by "Marisa Trampuz von Langendorf" Fellowship for Neuroscience.

\section{REFERENCES}

Ayton, S., Lei, P., and Bush, A. I. (2013). Metallostasis in Alzheimer's disease. Free Radic. Biol. Med. 62, 76-89. doi: 10.1016/j.freeradbiomed.2012.10.558

Baur, J. A., and Sinclair, D. A. (2006). Therapeutic potential of resveratrol: the in vivo evidence. Nat. Rev. Drug Discov. 5, 493-506. doi: 10.1038/nrd2060

Belguendouz, L., Fremont, L., and Linard, A. (1997). Resveratrol inhibits metal ion-dependent and independent peroxidation of porcine low-density lipoproteins. Biochem. Pharmacol. 53, 1347-1355. doi: 10.1016/s0006-2952(96) 00820-9

Billard, J. M. (2006). Ageing, hippocampal synaptic activity and magnesium. Magnes. Res. 19, 199-215. doi: 10.1684/mrh.2006.0063

Boillee, S., Vande Velde, C., and Cleveland, D. W. (2006). ALS: a disease of motor neurons and their nonneuronal neighbors. Neuron 52, 39-59. doi: 10.1016/j. neuron.2006.09.018

Bolognin, S., Messori, L., and Zatta, P. (2009). Metal ion physiopathology in neurodegenerative disorders. Neuromolecular Med. 11, 223-238. doi: 10. 1007/s12017-009-8102-1

Bolognin, S., Messori, L., Drago, D., Gabbiani, C., Cendron, L., and Zatta, P. (2011). Aluminum, copper, iron and zinc differentially alter amyloid-Abeta (1- 
42) aggregation and toxicity. Int. J. Biochem. Cell Biol. 43, 877-885. doi: 10. 1016/j.biocel.2011.02.009

Bolognin, S., Zatta, P., Lorenzetto, E., Valenti, M. T., and Buffelli, M. (2013). $\beta$-Amyloid-aluminum complex alters cytoskeletal stability and increases ROS production in cortical neurons. Neurochem. Int. 62, 566-574. doi: 10.1016/j. neuint.2013.02.008

Bordone, L., and Guarente, L. (2005). Calorie restriction, SIRT1 and metabolism: understanding longevity. Nat. Rev. Mol. Cell Biol. 6, 298-305. doi: 10. $1038 / \mathrm{nrm} 1616$

Bourzac, K. (2012). Interventions: live long and prosper. Nature 492, S18-S20. doi: $10.1038 / 492$ s 18 a

Brewer, G. J. (2012). Copper excess, zinc deficiency and cognition loss in Alzheimer's disease. Biofactors 38, 107-113. doi: 10.1002/biof.1005

Breydo, L., and Uversky, V. N. (2011). Role of metal ions in aggregation of intrinsically disordered proteins in neurodegenerative diseases. Metallomics 3, 1163-1180. doi: 10.1039/c1mt00106j

Bush, A. I. (2008). Drug development based on the metals hypothesis of Alzheimer's disease. J. Alzheimers Dis. 15, 223-240.

Cai, Z., Yan, L. J., and Ratka, A. (2013). Telomere shortening and Alzheimer's disease. Neuromolecular Med. 15, 25-48. doi: 10.1007/s12017-012-8207-9

Capiralla, H., Vingtdeux, V., Zhao, H., Sankowski, R., Al-Abed, Y., Davies, P., et al. (2012). Resveratrol mitigates lipopolysaccharide- and Abeta-mediated microglial inflammation by inhibiting the TLR4/NF-kappaB/STAT signaling cascade. J. Neurochem. 120, 461-472. doi: 10.1111/j.1471-4159.2011.07594.x

Chang, J., Rimando, A., Pallas, M., Camins, A., Porquet, D., Reeves, J., et al. (2012). Low-dose pterostilbene, but not resveratrol, is a potent neuromodulator in aging and Alzheimer's disease. Neurobiol. Aging 33, 2062-2071. doi: 10.1016/j. neurobiolaging.2011.08.015

Chen, M. L., Yi, L., Jin, X., Liang, X. Y., Zhou, Y., Zhang, T., et al. (2013). Resveratrol attenuates vascular endothelial inflammation by inducing autophagy through the cAMP signaling pathway. Autophagy 9, 2033-2045. doi: 10.4161/auto.26336

Chen, W. T., Liao, Y. H., Yu, H. M., Cheng, I. H., and Chen, Y. R. (2011). Distinct effects of $\mathrm{Zn} 2+, \mathrm{Cu} 2+, \mathrm{Fe} 3+$ and $\mathrm{Al} 3+$ on amyloid-beta stability, oligomerization and aggregation: amyloid-beta destabilization promotes annular protofibril formation. J. Biol. Chem. 286, 9646-9656. doi: 10.1074/jbc.m110.177246

Choi, K. M., Lee, H. L., Kwon, Y. Y., Kang, M. S., Lee, S. K., and Lee, C. K. (2013). Enhancement of mitochondrial function correlates with the extension of lifespan by caloric restriction and caloric restriction mimetics in yeast. Biochem. Biophys. Res. Commun. 441, 236-242. doi: 10.1016/j.bbrc.2013.10.049

ClinicalTrials.gov [Internet]. (2014). Bethesda (MD): National Library of Medicine (US). [Accessed].

Corona, G., Vauzour, D., Hercelin, J., Williams, C. M., and Spencer, J. P. E. (2013). Phenolic acid intake, delivered via moderate champagne wine consumption, improves spatial working memory via the modulation of hippocampal and cortical protein expression/activation. Antioxid. Redox Signal. 19, 1676-1689. doi: 10.1089/ars.2012.5142

Crespo, A. C., Silva, B., Marques, L., Marcelino, E., Maruta, C., Costa, S., et al. (2014). Genetic and biochemical markers in patients with Alzheimer's disease support a concerted systemic iron homeostasis dysregulation. Neurobiol. Aging 35, 777-785. doi: 10.1016/j.neurobiolaging.2013.10.078

Crouch, P. J., White, A. R., and Bush, A. I. (2007). The modulation of metal bioavailability as a therapeutic strategy for the treatment of Alzheimer's disease. FEBS J. 274, 3775-3783. doi: 10.1111/j.1742-4658.2007.05918.x

de la Lastra, C. A., and Villegas, I. (2007). Resveratrol as an antioxidant and prooxidant agent: mechanisms and clinical implications. Biochem. Soc. Trans. 35, 1156-1160. doi: 10.1042/bst0351156

Desquiret-Dumas, V., Gueguen, N., Leman, G., Baron, S., Nivet-Antoine, V., Chupin, S., et al. (2013). Resveratrol induces a mitochondrial complex Idependent increase in NADH oxidation responsible for sirtuin activation in liver cells. J. Biol. Chem. 288, 36662-36675. doi: 10.1074/jbc.M113.466490

Dixon, S. J., Lemberg, K. M., Lamprecht, M. R., Skouta, R., Zaitsev, E. M., Gleason, C. E., et al. (2012). Ferroptosis: an iron-dependent form of nonapoptotic cell death. Cell 149, 1060-1072. doi: 10.1016/j.cell.2012.03.042

Donmez, G. (2012). The neurobiology of sirtuins and their role in neurodegeneration. Trends Pharmacol. Sci. 33, 494-501. doi: 10.1016/j.tips.2012.05.007

Donmez, G., Wang, D., Cohen, D. E., and Guarente, L. (2010). SIRT1 suppresses beta-amyloid production by activating the alpha-secretase gene ADAM10. Cell 142, 320-332. doi: 10.1016/j.cell.2010.06.020
Doody, R. S., Thomas, R. G., Farlow, M., Iwatsubo, T., Vellas, B., Joffe, S., et al. (2014). Phase 3 trials of solanezumab for mild-to-moderate Alzheimer's disease. N. Engl. J. Med. 370, 311-321. doi: 10.1056/NEJMoa1312889

Duce, J. A., and Bush, A. I. (2010). Biological metals and Alzheimer's disease: implications for therapeutics and diagnostics. Prog. Neurobiol. 92, 1-18. doi: 10. 1016/j.pneurobio.2010.04.003

Duce, J. A., Tsatsanis, A., Cater, M. A., James, S. A., Robb, E., Wikhe, K., et al. (2010). Iron-export ferroxidase activity of beta-amyloid precursor protein is inhibited by zinc in Alzheimer's disease. Cell 142, 857-867. doi: 10.1016/j.cell. 2010.08.014

Faux, N. G., Ritchie, C. W., Gunn, A., Rembach, A., Tsatsanis, A., Bedo, J., et al. (2010). PBT2 rapidly improves cognition in Alzheimer's disease: additional phase II analyses. J. Alzheimers Dis. 20, 509-516. doi: 10.3233/JAD-2010-1390

Finney, L. A., and O'halloran, T. V. (2003). Transition metal speciation in the cell: insights from the chemistry of metal ion receptors. Science 300, 931-936. doi: 10. 1126/science.1085049

Frozza, R. L., Bernardi, A., Hoppe, J. B., Meneghetti, A. B., Battastini, A. M., Pohlmann, A. R., et al. (2013). Lipid-core nanocapsules improve the effects of resveratrol against Abeta-induced neuroinflammation. J. Biomed. Nanotechnol. 9, 2086-2104. doi: 10.1166/jbn.2013.1709

Gaier, E. D., Eipper, B. A., and Mains, R. E. (2013). Copper signaling in the mammalian nervous system: synaptic effects. J. Neurosci. Res. 91, 2-19. doi: 10. 1002/jnr.23143

Giuliani, D., Bitto, A., Galantucci, M., Zaffe, D., Ottani, A., Irrera, N., et al. (2014). Melanocortins protect against progression of Alzheimer's disease in tripletransgenic mice by targeting multiple pathophysiological pathways. Neurobiol. Aging 35, 537-547. doi: 10.1016/j.neurobiolaging.2013.08.030

Goldberg, D. M., Yan, J., and Soleas, G. J. (2003). Absorption of three wine-related polyphenols in three different matrices by healthy subjects. Clin. Biochem. 36, 79-87. doi: 10.1016/s0009-9120(02)00397-1

Gomes, A. P., Price, N. L., Ling, A. J., Moslehi, J. J., Montgomery, M. K., Rajman, L., et al. (2013). Declining $\mathrm{NAD}(+)$ induces a pseudohypoxic state disrupting nuclear-mitochondrial communication during aging. Cell 155, 1624-1638. doi: 10.1016/j.cell.2013.11.037

Gonzalez-Dominguez, R., Garcia-Barrera, T., and Gomez-Ariza, J. L. (2014). Characterization of metal profiles in serum during the progression of Alzheimer's disease. Metallomics 6, 292-300. doi: 10.1039/c3mt00301a

Granzotto, A., Bolognin, S., Scancar, J., Milacic, R., and Zatta, P. (2011). $\beta$-amyloid toxicity increases with hydrophobicity in the presence of metal ions. Monatsh. Chem. 142, 421-430. doi: 10.1007/s00706-011-0470-1

Granzotto, A., and Zatta, P. (2011). Resveratrol acts not through anti-aggregative pathways but mainly via its scavenging properties against Abeta and Abeta-metal complexes toxicity. PLoS One 6:e21565. doi: 10.1371/journal.pone.0021565

Halagappa, V. K., Guo, Z., Pearson, M., Matsuoka, Y., Cutler, R. G., Laferla, F. M., et al. (2007). Intermittent fasting and caloric restriction ameliorate age-related behavioral deficits in the triple-transgenic mouse model of Alzheimer's disease. Neurobiol. Dis. 26, 212-220. doi: 10.1016/j.nbd.2006.12.019

Hardy, J. A., and Higgins, G. A. (1992). Alzheimer's disease: the amyloid cascade hypothesis. Science 256, 184-185. doi: 10.1126/science.1566067

Heneka, M. T., Kummer, M. P., Stutz, A., Delekate, A., Schwartz, S., Vieira-Saecker, A., et al. (2013). NLRP3 is activated in Alzheimer's disease and contributes to pathology in APP/PS1 mice. Nature 493, 674-678. doi: 10.1038/nature 11729

Herrup, K. (2010). Reimagining Alzheimer's disease-an age-based hypothesis. J. Neurosci. 30, 16755-16762. doi: 10.1523/JNEUROSCI.4521-10.2010

Herskovits, A. Z., and Guarente, L. (2014). SIRT1 in neurodevelopment and brain senescence. Neuron 81, 471-483. doi: 10.1016/j.neuron.2014.01.028

Howitz, K. T., Bitterman, K. J., Cohen, H. Y., Lamming, D. W., Lavu, S., Wood, J. G., et al. (2003). Small molecule activators of sirtuins extend Saccharomyces cerevisiae lifespan. Nature 425, 191-196. doi: 10.1038/nature01960

James, S. A., Volitakis, I., Adlard, P. A., Duce, J. A., Masters, C. L., Cherny, R. A., et al. (2012). Elevated labile $\mathrm{Cu}$ is associated with oxidative pathology in Alzheimer disease. Free Radic. Biol. Med. 52, 298-302. doi: 10.1016/j. freeradbiomed.2011.10.446

Jayasena, T., Poljak, A., Smythe, G., Braidy, N., Munch, G., and Sachdev, P. (2013). The role of polyphenols in the modulation of sirtuins and other pathways involved in Alzheimer's disease. Ageing Res. Rev. 12, 867-883. doi: 10.1016/j.arr. 2013.06.003 
Jellinger, K. A. (2013). The relevance of metals in the pathophysiology of neurodegeneration, pathological considerations. Int. Rev. Neurobiol. 110, 1-47. doi: 10. 1016/b978-0-12-410502-7.00002-8

Joseph, J. A., Fisher, D. R., Cheng, V., Rimando, A. M., and Shukitt-Hale, B. (2008). Cellular and behavioral effects of stilbene resveratrol analogues: implications for reducing the deleterious effects of aging. J. Agric. Food Chem. 56, 10544-10551. doi: 10.1021/jf802279h

Khan, R. S., Fonseca-Kelly, Z., Callinan, C., Zuo, L., Sachdeva, M. M., and Shindler, K. S. (2012). SIRT1 activating compounds reduce oxidative stress and prevent cell death in neuronal cells. Front. Cell. Neurosci. 6:63. doi: 10.3389/fncel.2012. 00063

Kim, D., Nguyen, M. D., Dobbin, M. M., Fischer, A., Sananbenesi, F., Rodgers, J. T., et al. (2007). SIRT1 deacetylase protects against neurodegeneration in models for Alzheimer's disease and amyotrophic lateral sclerosis. EMBO J. 26, 31693179. doi: 10.1038/sj.emboj.7601758

Krstic, D., and Knuesel, I. (2013). Deciphering the mechanism underlying lateonset alzheimer disease. Nat. Rev. Neurol. 9, 25-34. doi: 10.1038/nrneurol. 2012.236

Kumar, V., Bal, A., and Gill, K. D. (2009). Susceptibility of mitochondrial superoxide dismutase to aluminium induced oxidative damage. Toxicology 255, 117123. doi: 10.1016/j.tox.2008.10.009

Lagouge, M., Argmann, C., Gerhart-Hines, Z., Meziane, H., Lerin, C., Daussin, F., et al. (2006). Resveratrol improves mitochondrial function and protects against metabolic disease by activating SIRT1 and PGC-1alpha. Cell 127, 1109-1122. doi: 10.1016/j.cell.2006.11.013

Leonard, S. S., Xia, C., Jiang, B. H., Stinefelt, B., Klandorf, H., Harris, G. K., et al. (2003). Resveratrol scavenges reactive oxygen species and effects radical-induced cellular responses. Biochem. Biophys. Res. Commun. 309, 1017-1026. doi: 10. 1016/j.bbrc.2003.08.105

Liu, T., and Bitan, G. (2012). Modulating self-assembly of amyloidogenic proteins as a therapeutic approach for neurodegenerative diseases: strategies and mechanisms. ChemMedChem 7, 359-374. doi: 10.1002/cmdc.201100585

Liu, G., Men, P., Zhu, X., and Perry, G. (2012). Iron chelation and nanoparticle target delivery in the development of new multifunctional disease-modifying drugs for Alzheimer's disease. Ther. Deliv. 3, 571-574. doi: 10.4155/tde. 12.32

López-Otín, C., Blasco, M. A., Partridge, L., Serrano, M., and Kroemer, G. (2013). The hallmarks of aging. Cell 153, 1194-1217. doi: 10.1016/j.cell.2013.05.039

Marambaud, P., Zhao, H., and Davies, P. (2005). Resveratrol promotes clearance of Alzheimer's disease amyloid-beta peptides. J. Biol. Chem. 280, 37377-37382. doi: 10.1074/jbc.m508246200

Mathur, S., Glogowska, A., Mcavoy, E., Righolt, C., Rutherford, J., Willing, C., et al. (2014). Three-dimensional quantitative imaging of telomeres in buccal cells identifies mild, moderate and severe Alzheimer's disease patients. J. Alzheimers Dis. 39, 35-48. doi: 10.3233/JAD-130866

McGeer, P. L., and McGeer, E. G. (2013). The amyloid cascade-inflammatory hypothesis of Alzheimer disease: implications for therapy. Acta Neuropathol. 126, 479-497. doi: 10.1007/s00401-013-1177-7

Medeiros, R., Chabrier, M. A., and Laferla, F. M. (2013). Elucidating the triggers, progression and effects of Alzheimer's disease. J. Alzheimers Dis. 33(Suppl. 1), S195-S210. doi: 10.3233/JAD-2012-129009

Min, S. W., Cho, S. H., Zhou, Y., Schroeder, S., Haroutunian, V., Seeley, W. W., et al. (2010). Acetylation of tau inhibits its degradation and contributes to tauopathy. Neuron 67, 953-966. doi: 10.1016/j.neuron.2010.08.044

Mucke, L., and Selkoe, D. J. (2012). Neurotoxicity of amyloid beta-protein: synaptic and network dysfunction. Cold Spring Harb. Perspect. Med. 2:a006338. doi: 10. 1101/cshperspect.a006338

Mudher, A., and Lovestone, S. (2002). Alzheimer's disease-do tauists and baptists finally shake hands? Trends Neurosci. 25, 22-26. doi: 10.1016/s01662236(00)02031-2

Muqbil, I., Beck, F. W., Bao, B., Sarkar, F. H., Mohammad, R. M., Hadi, S. M., et al. (2012). Old wine in a new bottle: the Warburg effect and anticancer mechanisms of resveratrol. Curr. Pharm. Des. 18, 1645-1654. doi: 10. 2174/138161212799958567

Ogas, T., Kondratyuk, T. P., and Pezzuto, J. M. (2013). Resveratrol analogs: promising chemopreventive agents. Ann. N Y Acad. Sci. 1290, 21-29. doi: 10.1111/nyas. 12196

Palacios, J. A., Herranz, D., De Bonis, M. L., Velasco, S., Serrano, M., and Blasco, M. A. (2010). SIRT1 contributes to telomere maintenance and augments global homologous recombination. J. Cell. Biol. 191, 1299-1313. doi: 10. 1083/jcb.201005160

Panza, F., Frisardi, V., Seripa, D., Logroscino, G., Santamato, A., Imbimbo, B. P., et al. (2012). Alcohol consumption in mild cognitive impairment and dementia: harmful or neuroprotective? Int. J. Geriatr. Psychiatry 27, 1218-1238. doi: 10. 1002/gps.3772

Park, S. J., Ahmad, F., Philp, A., Baar, K., Williams, T., Luo, H., et al. (2012). Resveratrol ameliorates aging-related metabolic phenotypes by inhibiting cAMP phosphodiesterases. Cell 148, 421-433. doi: 10.1016/j.cell.2012.01.017

Perl, D. P. (2006). Exposure to aluminium and the subsequent development of a disorder with features of Alzheimer's disease. J. Neurol. Neurosurg. Psychiatry 77:811. doi: 10.1136/jnnp.2006.090613

Pezzuto, J. M., Kondratyuk, T. P., and Ogas, T. (2013). Resveratrol derivatives: a patent review (2009 - 2012). Expert Opin. Ther. Pat. 23, 1529-1546. doi: 10. $1517 / 13543776.2013 .834888$

Pithadia, A. S., and Lim, M. H. (2012). Metal-associated amyloid-beta species in Alzheimer's disease. Curr. Opin. Chem. Biol. 16, 67-73. doi: 10.1016/j.cbpa.2012. 01.016

Porat, Y., Abramowitz, A., and Gazit, E. (2006). Inhibition of amyloid fibril formation by polyphenols: structural similarity and aromatic interactions as a common inhibition mechanism. Chem. Biol. Drug Des. 67, 27-37. doi: 10.1111/j. 1747-0285.2005.00318.x

Querfurth, H. W., and Laferla, F. M. (2010). Alzheimer's disease. N. Engl. J. Med. 362, 329-344. doi: 10.1056/NEJMra0909142

Rahman, I., Biswas, S. K., and Kirkham, P. A. (2006). Regulation of inflammation and redox signaling by dietary polyphenols. Biochem. Pharmacol. 72, 1439-1452. doi: 10.1016/j.bcp.2006.07.004

Reitz, C. (2012). Alzheimer's disease and the amyloid cascade hypothesis: a critical review. Int. J. Alzheimers Dis. 2012:369808. doi: 10.1155/2012/369808

Renaud, S., and De Lorgeril, M. (1992). Wine, alcohol, platelets and the French paradox for coronary heart disease. Lancet 339, 1523-1526. doi: 10.1016/01406736(92)91277-f

Rivière, C., Richard, T., Quentin, L., Krisa, S., Merillon, J. M., and Monti, J. P. (2007). Inhibitory activity of stilbenes on Alzheimer's beta-amyloid fibrils in vitro. Bioorg. Med. Chem. 15, 1160-1167. doi: 10.1016/j.bmc.2006. 09.069

Rizzuto, R., De Stefani, D., Raffaello, A., and Mammucari, C. (2012). Mitochondria as sensors and regulators of calcium signalling. Nat. Rev. Mol. Cell Biol. 13, 566578. doi: 10.1038/nrm 3412

Roberts, B. R., Ryan, T. M., Bush, A. I., Masters, C. L., and Duce, J. A. (2012). The role of metallobiology and amyloid-beta peptides in Alzheimer's disease. J. Neurochem. 120(Suppl. 1), 149-166. doi: 10.1111/j.1471-4159.2011. 07500.x

Sayre, L. M., Perry, G., Harris, P. L., Liu, Y., Schubert, K. A., and Smith, M. A. (2000). In situ oxidative catalysis by neurofibrillary tangles and senile plaques in Alzheimer's disease: a central role for bound transition metals. J. Neurochem. 74, 270-279. doi: 10.1046/j.1471-4159.2000.0740270.x

Sekler, I., and Silverman, W. F. (2012). Zinc homeostasis and signaling in glia. Glia 60, 843-850. doi: 10.1002/glia.22286

Sensi, S. L., Paoletti, P., Bush, A. I., and Sekler, I. (2009). Zinc in the physiology and pathology of the CNS. Nat. Rev. Neurosci. 10, 780-791. doi: 10.1038/nrn2734

Sharma, D. R., Sunkaria, A., Wani, W. Y., Sharma, R. K., Kandimalla, R. J., Bal, A., et al. (2013). Aluminium induced oxidative stress results in decreased mitochondrial biogenesis via modulation of PGC-1alpha expression. Toxicol. Appl. Pharmacol. 273, 365-380. doi: 10.1016/j.taap.2013.09.012

Shin, S. M., Cho, I. J., and Kim, S. G. (2009). Resveratrol protects mitochondria against oxidative stress through AMP-activated protein kinasemediated glycogen synthase kinase-3beta inhibition downstream of poly(ADPribose)polymerase-LKB1 pathway. Mol. Pharmacol. 76, 884-895. doi: 10. 1124/mol.109.058479

Siemann, E. H., and Creasy, L. L. (1992). Concentration of the Phytoalexin resveratrol in wine. Am. J. Enol. Vitic. 43, 49-52.

Singh, I., Sagare, A. P., Coma, M., Perlmutter, D., Gelein, R., Bell, R. D., et al. (2013). Low levels of copper disrupt brain amyloid-beta homeostasis by altering its production and clearance. Proc. Natl. Acad. Sci. U S A 110, 14771-14776. doi: 10.1073/pnas.1302212110

Tadolini, B., Juliano, C., Piu, L., Franconi, F., and Cabrini, L. (2000). Resveratrol inhibition of lipid peroxidation. Free Radic. Res. 33, 105-114. doi: 10. 1080/10715760000300661 
Tamboli, V., Defant, A., Mancini, I., and Tosi, P. (2011). A study of resveratrolcopper complexes by electrospray ionization mass spectrometry and density functional theory calculations. Rapid Commun. Mass Spectrom. 25, 526-532. doi: $10.1002 / \mathrm{rcm} .4883$

Uchiumi, F., Watanabe, T., Hasegawa, S., Hoshi, T., Higami, Y., and Tanuma, S. (2011). The effect of resveratrol on the Werner syndrome RecQ helicase gene and telomerase activity. Curr. Aging Sci. 4, 1-7. doi: 10.2174/1874612811104 010001

Vingtdeux, V., Giliberto, L., Zhao, H., Chandakkar, P., Wu, Q., Simon, J. E., et al. (2010). AMP-activated protein kinase signaling activation by resveratrol modulates amyloid-beta peptide metabolism. J. Biol. Chem. 285, 9100-9113. doi: 10.1074/jbc.m109.060061

Walton, J. R. (2013). Aluminum involvement in the progression of Alzheimer's disease. J. Alzheimers Dis. 35, 7-43. doi: 10.3233/JAD-121909

Wang, J., Ho, L., Zhao, Z., Seror, I., Humala, N., Dickstein, D. L., et al. (2006). Moderate consumption of Cabernet Sauvignon attenuates A beta neuropathology in a mouse model of Alzheimer's disease. FASEB J. 20, 2313-2320. doi: 10.1096/fj. 06-6281com

Wang, X., Wang, W., Li, L., Perry, G., Lee, H. G., and Zhu, X. (2013). Oxidative stress and mitochondrial dysfunction in Alzheimer's disease. Biochim. Biophys. Acta doi: 10.1016/j.bbadis.2013.10.015. [Epub ahead of print].

Weinreb, O., Mandel, S., Youdim, M. B., and Amit, T. (2013). Targeting dysregulation of brain iron homeostasis in Parkinson's disease by iron chelators. Free Radic. Biol. Med. 62, 52-64. doi: 10.1016/j.freeradbiomed.2013.01.017

Weinstein, G., Beiser, A. S., Choi, S. H., Preis, S. R., Chen, T. C., Vorgas, D., et al. (2014). Serum brain-derived neurotrophic factor and the risk for dementia: the Framingham Heart Study. JAMA Neurol. 71, 55-61. doi: 10.1001/jamaneurol. 2013.4781

Wu, Z., Du, Y., Xue, H., Wu, Y., and Zhou, B. (2012). Aluminum induces neurodegeneration and its toxicity arises from increased iron accumulation and reactive oxygen species (ROS) production. Neurobiol. Aging 33, 199.e1-199.e12. doi: 10. 1016/j.neurobiolaging.2010.06.018

Ye, J., Liu, Z., Wei, J., Lu, L., Huang, Y., Luo, L., et al. (2013). Protective effect of SIRT1 on toxicity of microglial-derived factors induced by LPS to PC12 cells via the p53-caspase-3-dependent apoptotic pathway. Neurosci. Lett. 553, 72-77. doi: 10.1016/j.neulet.2013.08.020

Zaky, A., Mohammad, B., Moftah, M., Kandeel, K. M., and Bassiouny, A. R. (2013). Apurinic/apyrimidinic endonuclease 1 is a key modulator of aluminum-induced neuroinflammation. BMC Neurosci. 14:26. doi: 10.1186/1471-2202-14-26

Zatta, P., Drago, D., Bolognin, S., and Sensi, S. L. (2009). Alzheimer's disease, metal ions and metal homeostatic therapy. Trends Pharmacol. Sci. 30, 346-355. doi: 10. 1016/j.tips.2009.05.002

Zatta, P., Kiss, T., Suwalsky, M., and Berthon, G. (2002). Aluminium(III) as a promoter of cellular oxidation. Coord. Chem. Rev. 228, 271-284. doi: 10. 1016/S0010-8545(02)00074-7

Zatta, P., Lucchini, R., Van Rensburg, S. J., and Taylor, A. (2003). The role of metals in neurodegenerative processes: aluminum, manganese, and zinc. Brain Res. Bull. 62, 15-28. doi: 10.1016/s0361-9230(03)00182-5

Zheng, L. F., Wei, Q. Y., Cai, Y. J., Fang, J. G., Zhou, B., Yang, L., et al. (2006). DNA damage induced by resveratrol and its synthetic analogues in the presence of $\mathrm{Cu}$ (II) ions: mechanism and structure-activity relationship. Free Radic. Biol. Med. 41, 1807-1816. doi: 10.1016/j.freeradbiomed.2006.09.007

Conflict of Interest Statement: The authors declare that the research was conducted in the absence of any commercial or financial relationships that could be construed as a potential conflict of interest.

Received: 04 March 2014; accepted: 28 April 2014; published online: 14 May 2014. Citation: Granzotto A and Zatta P (2014) Resveratrol and Alzheimer's disease: message in a bottle on red wine and cognition. Front. Aging Neurosci. 6:95. doi: 10.3389/fnagi. 2014.00095

This article was submitted to the journal Frontiers in Aging Neuroscience.

Copyright $\odot 2014$ Granzotto and Zatta. This is an open-access article distributed under the terms of the Creative Commons Attribution License (CC BY). The use, distribution or reproduction in other forums is permitted, provided the original author (s) or licensor are credited and that the original publication in this journal is cited, in accordance with accepted academic practice. No use, distribution or reproduction is permitted which does not comply with these terms. 